\title{
RASGOS PRECAPITALISTAS EN LA ORGANIZACIÓN INDUSTRIAL ARAGONESA (SIGLO XV)
}

\author{
J. Ángel Sesma Muñoz
}

Es muy poco lo que se sabe de las transformaciones estructurales de la economía aragonesa en la baja Edad Media. La marginación, en relación a las actividades mediterráneas, en los trabajos de investigación tradicionales, ha servido para dar por sentada la dependencia de Aragón con respecto a Cataluña - y en general del exterior-en todo lo concerniente al desarroJlo comercial, y, muy especialmente, al desenvolvimiento de una actividad manufacturera con fuerte incidencia en el mercado interior y alguna participación en el exterior.

Tras la crisis del siglo XIV y la redistribución de la renta, una parte considerable de la población campesina y urbana de Occidente accedió a la categoría de potenciales consumidores de productos hasta entonces reservados a núcleos minoritarios'. El fenómeno, general en Europa, impulsó decisivamente la transformación de las estructuras mercantiles e industriales que ya habían alcanzado una organización administrativa y una evolución técnica suficientes ${ }^{2}$. De todas las producciones afectadas por esta ampliación de la demanda, fue el sector textil el que más directamente se vió alterado, pues en un plazo muy

1. H. KF I ENBENZ, aLa iadustria en la Europa moderna (1500-1759)s, en P. VII.AR y otros, La industrialización europea. Estadios y tipos, Barcelona 1981, p. 11-82. M. MaLowist, «Quelques observations sur la structure de la production et du commerce du drap au cours du $\mathrm{XIV}^{e}$, et du $\mathrm{XV}^{e}$, siècle» en Produzione, commercio e consumo dei panni di lana (nei secoli XII-XVII), a cura di M. SPALLANZANI, Florencia 1976, p. 595-601.

${ }^{2}$ Además de los art. cits. en la nota anterior, ef. los trabajos recogidos en M. MALOWIST, Croissance et regression en Europe, XIV XVII ${ }^{e}$, siècles, París 1972: Produzione, commercio e consumo dei panni di lana, op. cit.; Produttività e tecnologie (nei secoli XII-XVII), a cura di S. MARtorn, Florencia 1981; las síntesis de Historia económica de Europa recientemente publicadas: C.M. Crpolla, Historia económica de la Europa preindustrial, Madrid 1976: C.M. Cipolla (ed.), Historia económica de Europa, (1). La Edad Media, Barcelona 1979; H.A. Miskimin, La economía de Europa en el alto Renacimiento (1300-1460), Madrid 1980; N.J.G. Pounds, Historia económica de la Europa medieval, Barcelona 1981. 
breve de tiempo tuvo que transformar su organización para poder hacer frente a las exigencias de una clientela popular que reclamaba productos de características formales según sus gustos y necesidades, pero con un precio acorde a su capacidad económica. La industria textil pasó de producir tejidos de calidad en centros especializados, a fabricar un enorme volumen de mercancía de calidad ordinaria a precio reducido.

Por otra parte, el propio incremento de la renta y la modificación de los gustos populares - tendentes a buscar su identificación con los grupos superiores - provocaron, simultáneamente, la artesanía doméstica, que hasta entonces había abastecido al núcleo familiar o local de los productos textiles necesarios, cubriendo, sin apenas organización particular y manteniéndose estrechamente unida al sistema agrario, las mínimas necesidades de la gran masa de población. Este sistema artesanal contaba con una prolongación a nivel urbano, existiendo pequeños talleres u obradores domésticos, encastrados en el entramado económico y social de las pequeñas ciudades agrícolas, que producian tejidos de baja calidad, en cantidades reducidas, comercializados en los mercados locales ${ }^{3}$.

Los estímulos económicos propiciados por el incremento de la demanda, y distribuidos de manera bastante uniforme por Occidente, favorecieron el desarrollo de centros productores, no especialmente al principio, sino imitadores de géneros y calidades exteriores reclamadas por el consumo comarcal-regional, a precios más baratos. El impulso de la pequeña artesanía local, donde se produjo, vino de la inclusión del elemento mercantil en el mundo de la producción, armonizando oferta y demanda y aplicando las técnicas propias de sus negocios al ejercicio fabril ${ }^{4}$. Aparece, pues, la especialización de las funciones, diferenciándose entre empresarios y artesanos; mientras los primeros se responsabilizan de la distribución del producto y la coordinación del ciclo productivo, enormemente complejo y arriesgado, los segundos organizan el proceso de trabajo que aparece repartido en distintas manipulaciones encomendadas a gremios diversos. Ambas funciones aparecen independientes desde el punto de vista técnico, aunque muy pronto se ve el predominio empresarial basado en el aporte del capital y, sobre todo, de los conocimientos de gestión y de

3 Para Castilla esta transformación está perfectamente analizada por P. IRADIEL, Evolución de la industria textil casteliana en los siglos XII-XVI, Salamanca 1974, y más recientemente en «Estructuras agrarias y modelos de organización industrial precapitalista en Castilla», Stvdia Historica. Historia Medieval, vol. I (1983), p. 87-112.

4 R.S. Dupt.Essis y M.C. HowEL. « Reconsidering the Early Modern Urban Economy: The eases of Leiden and Lillen, Past and Present, 94 (1982), p. 49-84. Presentan la respuesta dada a los cambios de la demanda por centros urbanos de producción modesta. 
canalización de la demanda: este predominio se mostrará incuestionable a través de las rígidas ordenanzas gremiales ${ }^{5}$.

Es, pues, hasta cierto punto frecuente la aparición temprana de rasgos capitalistas en manifestaciones industriales, en el seno de sociedades definidas como agrarias, mucho antes de la «revolución industrial», sin que ello permita adelantar el inicio de la industrialización ${ }^{6}$, máxime porque la transformación sólo adquiere cierta consistencia en el sector textil lanero y en la industria del metal, manteniéndose el resto de actividades en un estadio artesanal más puro.

Aragón, por las transformaciones interiores y exteriores, inició desde finales del siglo XII un profundo proceso que le convirtió, tras la crisis del XIV, en un importante productor de materias primas necesarias a la gran industria europea; de alimentos (lana, azafrán, trigo, aceite); en un rico mercado de productos diversos (desde tejidos y objetos metálicos hasta especias); y, por su situación en el sistema de comunicaciones interiores, en un privilegiado centro de distribución de mercancías mediterráneas hacia el ámbito peninsular y, viceversa, desde el Cantábrico y el interior hacia la costa. Con esta evolución se irá creando un fuerte grupo mercantil, que procedente de fuera del reino o surgido de las propias familias aragonesas - o conversas - emprenderá la tarea de establecer un modelo de actividad comercial e industrial propio, a imagen del existente en otros centros económicos de Occidente, aunque a la escala impuesta por la propia capacidad del reino.

Circunscribiéndonos al marco de la producción textil, se comprueba el constante crecimiento de la demanda de paños de calidad media por parte de un mercado en expansión, tanto en el interior como para la reexportación. El punto álgido se alcanza en el decenio 60-70 del siglo XIV, en el cual ya de manera clara las corrientes mercantiles de ámbito internacional intentan el monopolio para sus producciones $y$,

5 J. SchlumbotiM, «Relations of Production - productive forces - crisis in proto-industrialization», en P. KRIEDTE, H. MEDICK y J. SCHL UMBOHM, Industrialization before Industrialization. Cambridge 1981, p. 94-125. El trabajo analiza la inestabilidad de los pequeños productores que deben recurrir al capital mercantil para colocar su producción, lo que es aprovechado por éste para forzar el endeudamiento y terminar con la libertad de los maestros.

${ }^{6}$ El interés por el estudio de la iadustria antes de la indusirialización y por el analisis de la actividad industrial dentro del proceso de crisis del feudalismo, es patente desde hace más de un decenio, aunque en España sea más reciente. Entre las aportaciones metodológicas más interesantes, destacan: P. KRIEDTE, H. MEDICK y J. SCHLUMBOHM, alndustrialization before Industrializationn, op. cit., vol. LXI (1979) de la Revue du Nord y Actas del Octavo Congreso Internacional de Historia Económica, Budapest 1982.

7 H. KalenBeNZ, El desarrollo económico de la Europa continental (1500-1750), Madrid 1977 , p. 105-131.

8 J.A. SESMA, Transformación social y revolución comercial en A ragón, durante la baja Edad Media, Madrid 1982. 
tras el fracaso, el abanico de ofertas para satisfacer la demanda se amplía hasta cubrir la práctica totalidad de tejidos de la gran industria europea.

En las Cortes Generales de Monzón de 1362, coincidiendo con un momento de gran agobio económico y militar del monarca y del reino de Aragón, los representantes catalanes consiguen que se apruebe la prohibición de importación de textiles en el territorio peninsular de la Corona, obligando con ello a los habitantes de Aragón, Valencia y Cataluña a equiparse con tejidos fabricados por la propia industria, cuya organización más desarrollada y capacitada para abastecer tan amplio y diverso mercado era, precisamente, la de Cataluña; cuando unos meses después se anuló tal medida, las Cortes aragonesas impusieron una tasa a los paños ingresados en el reino, no tanto con miras proteccionistas como de búsqueda de ingresos fiscales indirectos que permitieran un desahogo a las arcas comunes del General".

Esta última acción nos permite contemplar los pormenores relativos a la diversidad de géneros y calidades habitualmente comercializada en Aragón, pues las Cortes de 1376, al reorganizar las medidas fiscales sobre la importación textil establecieron una valoración estable a los paños más frecuentes, con el fin de unificar el gravamen por todas las fronteras sin afectar alteraciones secundarias del precio. La relación abarca desde los tejidos de lujo de calidad extra dedicados a los grupos superiores de la población (escarlatas y granas, especialmente de Douai, Lovaina, Gante y Londres), hasta los modestos paños catalanes y gascones (comunes) con una tasación de 8 a 14 veces menor que los primeros ${ }^{10}$.

9J.A. SeSma, aLa fijación de fronteras económicas entre los Estados de la Corona de Aragón», Aragón en la Edad Media, V (1983), p. 141-166.

${ }^{10}$ De las Cortes de Monzón de 1376 se conservan las actas del proceso en ADZ, ms. 2 , f. $165-250$. 
TASACIÓN DE PAÑOS EXTRANJEROS COMERCIALIZADOS EN ARAGÓN, REALIZADA EN LAS CORTES DE MONZÓN DE 1376

Tipo de paño y procedencia

Precio en lb.j.

Escarlata de Duay (Douai) .

70 la pieza

Escarlata de Lohan (Lovaina)

40 la pieza

Escarlatas viadas de Gant (Gante)

40 la pieza

Grana de Londres

40 la pieza

Grana de Mellinas (Malinas) .

35 la pieza

Grana de Perpenyan (Perpiñán)

30 la pieza

Bruxellas (Bruselas) de la mayor suert

27 la pieza

Braxellas de la menor suert

25 la pieza

Lohan de la mayor suert

25 la pieza

Molina (Malinas?)

20 la pieza

Ypres de la mayor suert ................ 20 la pieza

Viados de Gant . . . . . . . . . . . . . . . . . . . . 20 la pieza

Ypres de la menor suert .................. 18 la pieza

Lohan de la menor suert ................. 18 la pieza

Londres de Bristo $($ Bristol) . . . . . . . . . . . . . . 18 la pieza

Filaffort (Vilforte) . . . . . . . . . . . . . . 15 la pieza

Vervi (Wervicq) . . . . . . . . . . . . . . 12 la pieza

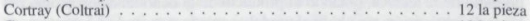

Carcassona . . . . . . . . . . . . . . . . 10 la pieza

Perpenyan .................... 10 la pieza

Ripoll ......................... . . . la pieza

Campredon (Camprodón) ... . . . . . . . . . . 8 la pieza

Sant Johan de las Abadessas . . . . . . . . . . . . . . 8 la pieza

Girona ... . . . . . . . . . . . . . 8 la pieza

Sant Johan de Ampurias . . . . . . . . . . . . . . . 8 la pieza

Limos $\{$ Limogest . . . . . . . . . . . . . . . . . . . . . 7 la pieza

Montoliu ..................... 7 la pieza

Barchinona (Barcelona) . . . . . . . . . . . . . . 7 la pieza

Bristo, Colcestre (Colchester y otros villatges) . . . . . . . 6 la docena

Pamias (Pamiers) . . . . . . . . . . . . . . . . . 6 la pieza

Tolosa (Toulouse) . . . . . . . . . . . . . . . . . . . . 6 la pieza

Vilapenxa ....................... 6 la pieza

Valencia, Moriella (Morella) y semblantes . . . . . . . . . 6 la pieza

Villatges de Guascunya (Gascuña) $\ldots \ldots \ldots \ldots \ldots \ldots \ldots$. 5 la pieza

Villafranca .................... 5 la pieza

Verga (Berga) ..................... 5 la pieza

Cardona .................... 5 la pieza

Solsona . . . . . . . . . . . . . . . . . . . . 5 la pieza

Lerida . . . . . . . . . . . . . . . . 5 la pieza

Puycerdan (Puigcerdá) ... . . . . . . . . . . . . 5 la pieza

Paños comunes que no alcanzan el precio de los de Puycerdan . . . . . . 5 la pieza 
Por otra parte, la existencia en Aragón de una elemental manufactura textil está fuera de duda. Las noticias anteriores a 1300 reflejan esta actividad tanto en la vertiente doméstica rural, con su manifestación dentro del marco señorial ${ }^{11}$, como la urbana, donde incluso los paños de Jaca y Huesca, con el apelativo de procedencia, se incorporan al comercio peninsular y aparecen mencionados en aranceles aduaneros ${ }^{12}$, y donde la monarquía interviene para regular el proceso de elaboración y vigilar el cumplimiento de las normas de fabricación en protección de los artesanos ${ }^{13}$. La mención de calderas de tinte en la práctica totalidad de ciudades ${ }^{14}$ y la presencia dispersa de tejedores ${ }^{15}$ en documentación del siglo XIII, nos ponen de manifiesto la existencia de una producción textil generalizada, pero muy poco profesionalizada.

A lo largo del siglo xIV la situación se transforma. A pesar de la carencia de datos precisos para trazar con cierta claridad las etapas de evolución, el resultado final, que luego analizaremos, permite entrever que, tras partir de los pequeños núcleos productores que por disponer de materia prima y mano de obra abundantes tienen capacidad de incrementar su producción, basada en la imitación de los paños extranjeros de mayor consume en la región, se pasa a una segunda etapa en la que se mantiene el nombre de la muestra como símbolo de garantía, y se finaliza, tras el dominio de la técnica, dotando al producto de la denominación propia del lugar de fabricación, sin aludir al mođelo copiado y pasando a competir con él en el mercado interior e, incluso, en el exterior, al poder presentar mejor precio.

11 En 1193 los templarios de Huesca compraron parte de un molino draper a don Gassión de Abós (AHN, cód 499, p. 25, núm. 53); en 1276 se documenta un molinotrapero entre las propiedades del señorío de Sesa (M. D. BArrios, Libro del castillo de Sesa, Zaragoza 1982. p. 83).

12 La leuda de Barcelona de 1222 cita pannus de Hosqua, VI d.; en el peaje de Candanchú. de 1295, aparece Carga de pannos de Jacca o de Lerida, XII, d. (M. GuaL, Vocabulario del comercio medieval, Tarragona 1968, p. 61 y 161).

13 Jaime I, en 1219, ordena que nadie prepare en Jaca más que pafios tejidos en la ciudad: treinta años más tarde les autoriza a teñir en todos los colores, de la misma manera que lo hacian los de Huesca y Lérida (A. Uвikto, Jaca: Docomentos municipales, Valencia 1975, docs. 44 y 60 ). En 1322, un privilegio de Jaime II, basado en los usos y costumbres antiguas. confirma la libertad de los ciudadanos y habitantes de Zaragoza para teñir paños destinados a la venta o a sy propio uso, en sodos Jos colores salyo el índigo (M. ABIZANDA, Colección de documentos inéditos del archivo municipal de Zaragozo, desde el reinado de Pedro III al de Juan II, Valencia 1924, p. 589).

14 Aparte de las ciudades de Jaca, Huesca y Zaragoza arriba mencionados, desde comienzos del siglo XII el tinte de la ciudad de Daroca era patrimonio regio, pasando luego al Temple y nuevamente al Rey, para ser, desde 1311, arrendado por los habitantes (J.L. CoRraL. Historia de Daroca. Zaragoza 1983, p. 109).

is Según el monedaje de 1284, en Huesca sólo se contabilizan seis tejedores (J.F. UTRILA, «El monedaje de Huesca de 1284n, Aragón en la Edad Media, I (1977), p. 1-50). 
La fase intermedia la encontramos apuntada documentalmente cuando entre los fueros promulgados en $1349^{16}$, con motivo de la peste negra y en evitación de trastornos salariales, se fijaron por ley los precios que podrían reclamar los baxadores por baxar paños de «Damis, Bruxillas, Mellinas, Monstreviller, Doay, Luna, Chalon, Florentin, viado de Gants -2 d. por codo $03 \mathrm{~d}$. si se repetía la operación-, «scarlata plana, scarlata viada» - 3 d. por codo o $4 \mathrm{~d}$. por doble proceso-y por cualquier otro tipo de paño, sólo un dinero, sin posible repetición; al referirse a las operaciones de: tejer, filar, peinar, barutar, arquiar, preparatorias del acabado final, se indica sencillamente que se continuará aplicando la tarifa anterior a la epidemia.

En cuanto al desenlace del fenómeno evolutivo, desde comienzos del siglo XV se aprecia el incremento de la producción y la mejora de la calidad; los paños denominados aragoneses o de lugares del reino aparecen ya en los mercados exteriores.

Así, la evaluación de géneros textiles enviada por el «veedor da fazendas portugués al recibidor de la alfondega de Lisboa incluye spanos do regno d'Aragã» junto a los de Bristol, Iprés, Brujas, etc. ${ }^{17}$; en 1419 , cuando las cortes castellanas de Madrid suplican al monarca la aprobación de una ordenanza que evite «los grandes dannos» producidos a los naturales de sus reinos «por entrar en ellos mercaderes extranjeros a vender pannos», mencionan expresamente a los gascones, navarros y aragoneses; $y$ otra ordenanza, ésta de 1442, al mencionar los paños de la Corona de Aragón más comercializados en Castilla, lo hace por este orden: «sanjuanes prietos y pardillos y de todos otros colores, pannos verbies de todos los colores de Valencia, pardillos de Zaragoza.... ${ }^{8}$. A mediados de siglo es continua la exportación desde Aragón de tejidos denominados por su origen: Tarazona, Añón, Calatayud, Daroca, Teruel, Híjar, Fortanete, Albarracín, Montalbán, Monzón, Aínsa, Broto, Sallent, Jaca, Huesca, Uncastillo, Tauste, Zaragoza. Los precios, calidades y colores son equiparables a los fabricados en los centros textiles más próximos - Cataluña, Valencia y Languedoc-con los que compite en el mercado interior y exterior. Todo permite pues suponer que el establecimiento de una industria textil aragonesa está concluido $^{19}$.

Pero para que la fase última pudiera cuajar plenamente se necesitaba, además, la modificación de la organización industrial y poner en relación el capital mercantil con la capacidad de trabajo. Los niveles modestos de

$16 \mathrm{G}$. Thlander, Fueros aragoneses desconocidos promulgados a consecuencia de la gran peste de 1348, Estocolmo 1959.

${ }^{17} \mathrm{Ch}$. VerL.INDEN, «Draps des Pays-Bas et du Nord-Ouest de l'Europe au Portugal au $\mathrm{XV}^{e}$, siècles, en Amuario Estudios Medievales, III (1966), p. 251-253.

${ }_{18}$ Cortes de León y Castilla, III, p. 18-19.

19 J.A. SesmA, Transformación social, op. cit. p. 21-27. 
ambos factores hacen muy difícil contar con información precisa que refleje los modelos y estadios sucesivos adoptados en la evolución; sólo una intensa búsqueda en documentación notarial de los siglos XIV y XV, muy abundante para los núcleos urbanos del reino, brindará el material que fije, desde una amplia perspectiva, la estructura de la industria pañera aragonesa, en su conjunto y en cada una de las fases de producción, así como la valoración y análisís de su particípación dentro del entramado económico y social del Reino y de la Corona.

De momento, los primeros resultados obtenidos permiten la aproximación al desarrollo general atendiendo a aspectos parciales, que pueden extrapolarse a la totalidad del proceso, y a casos concretos cuyo comportamiento se puede considerar representativo.

Una de las etapas del ciclo productivo más importante es la tintura, que incide en el precio del paño entre el 15 y el $30 \%$ en los de calidad media, y es desarrollada en gremio numeroso y potente. La tradición tintorera en Aragón estaba muy arraigada desde hacía siglos, y junto a los tintes tradicionales en la pañería doméstica - colores oscuros, cárdenos, pardos-es posible que se aplicaran tonos brillantes, próximos a los que desde mediados del siglo XV iban a ser adoptados por las clases pudientes para distinguirse del resto de la población ${ }^{20}$. De hecho, salvo en la zona norte del reino - Aínsa, Broto, Sallent- cuya producción se basaba casi exclusivamente en paños crudos o blancos, que eran exportados a Cataluña para su acabado y teñido, las demás áreas textiles tienen una buena técnica tintórea; a la zona del Somontano Jbérico llegan paños piezas tejidas en Calahorra, Ágreda, Osma y Sigienza" ; la pañería de Calatayud, cuyo producto principal se teñía de gris - pel de rata - obtenia también el bermejo y el verdegay; la de Teruel, posiblemente la de mayor dominio del tinte, produce verdes y azules de gran fuerza; y la de Zaragoza, que ha adquirido la primacía en cantidad y calidad, contando con artesanos extranjeros que han aportado su técnica, presenta entre sus producciones los colores bermejos, argentados, rosetes, etc.

Precisamente en Zaragoza, desde comienzos del siglo XV, se muestra ya plenamente lograda la síntesis entre el empresario y el artesano, que en diferentes modelos configurará, a partir de entonces, las relaciones capitaltrabajo, decisivas para el posterior desarrollo de la industrialización moderna.

En 1401 se firma ante notario ${ }^{22}$ la constitución de una compañía para explotar un modesto negocio de tinte entre un hombre de negocíos, Pedro

20 J. Hzers, "La mode et les marchés de draps de laine au Moye Agen, en Annales ESC, XXV (1971), p. 1093-1117.

21 P. IRADIEL, Evolución w, op. cit. p. 105; Estructuras agrarias... op. cit., p. I09.

22. AHPZ, Juan Blasco de Azuara, 1401. Registro, s.d.: Protocolo, f. 302-305 v. Apéndice. 
Olzina ${ }^{23}$, vecino de Zaragoza, tintorero, pero que dispone de una «tienda o botiga», y dos artesanos, Johan Brun y Pedro de Moya, tintoreros, habitantes en Zaragoza ${ }^{24}$.

Las instalaciones en donde realizarán el trabajo corresponden a un antiguo tinte familiar, que había sido de un tintorero llamado Johan del Pin y que ahora pertenecía a sus hijos ${ }^{25}$, que suponemos menores, porque el arriendo lo efectúa Pedro de Sant Vicient. Entre los gastos previstos por la compañía no se contempla la posibilidad de invertir en mejorar el utillaje ni el establecimiento.

Las cláusulas del contrato separan las funciones del capital y del trabajo. La primera es adjudicada exclusivamente a Pedro Olzina, que aporta el dinero (1000 sueldos jaqueses) «pora sustentación e mantenimiento de la dita conpanya e de las cosas necessarias son a la art e officio de tinturerias, en especial la adquisición de las materias primas para comenzar el negocio. Pero esta participación no es a su riesgo, sino que la suma invertida es, a su vez, recibida en comanda ${ }^{26}$ por los dos socios artesanos que aseguran su restitución al cabo del año de vigor del convenio, «quando vos dito Pedro Olzina seras contento de los ditos mil sueldos», lo que significa que más que una inversión es un préstamo cuyos intereses serán el 33\% de los beneficios obtenidos del trabajo de los dos tintoreros. Para controlar su negocio el contrato otorga a Olzina derechos totales en la administración y por ello cada sábado recibirá cuentas y explicaciones de la tarea realizada para que «veas lo que si faze en cada una semana en la dita razon o conpanya», a la vez que le entregaran «todos qualesquiere dineros que se prendran o recibran en l'obrador e tin", que los anotará en sus libros como

${ }^{23} \mathrm{El}$ apellido Olzina quizá sea de procedencia valenciana; en Aragón, hasta mediados del XV no aparece documentado con alguna frecuencia. Un Berenguer Olzina figura en la lista de cautivos presentada por Valencia en las negociaciones entre Jaime II y Tremecen, en 1327 (A. MAsiA, La Corona de Aragón y los Estados del norte de Africa, Barcelona 1951, p. 226): un Johan Olzina, tejedor, vive en Valencia antes de 1371, en que aparece citada su viuda (M. D. CABANES, Los monasterios valencianos. Su economía en el siglo XV, Valencia 1971. vol. II, p. 89); y otro Johan Olzina, armador de Menorca, participa activamente en el último tercio del siglo en el comercio de sal desde Cerdeña a las Baleares (C Masca, Aspersi dell' espansione economica catalano-aragonese nel Mediterraneo Occidentale, Milán 1966. p. 166). A mediados del XV, Juan Olzina será secretario de Alfonso V y los Olzina serán senores de la Honor de Huesa, lo que les permitira participar en la politica interior aragonesa. ocupando cargos en la Diputación del General; a fines del siglo un Pedro Olzina, alias Valencia, mercader aragonés, desarrolla una actividad comercial en el Bearn (J.A. La Diputación del reino de Aragón en la época de Fernando II, Zaragoza 1977, p. 274, 405, 409, 424 y 427).

${ }^{24} \mathrm{El}$ ser denominados «habitantes» indica su procedencia exterior, que podría muy bien ser castellana.

25 Un tintorero de este nombre aparece en documentación posterior, de 1426, por ejemplo. Véase supra.

26 AHPZ, Juan Blasco de Azuara, 1401, Protocolo, f. $307 \mathrm{y}^{\circ}$. 
«recepta» para cubrí los gastos ade aquello que a vos dito Pedro Olzina se devra por razon de las averias que de vos havremos conpradas o recebidas pora el dito tin»; cada tres meses se revisarán las cuentas, aunque no habrá reparto de beneficios hasta concluir el año. Cuando se agoten los primeros mil sueidos Olzina deberá aportar otros mil o la cantidad precisada, pero podrá recuperarlos inmediatamente con los primeros ingresos obtenidos por la companifa. Una manera de controlar el trabajo y de aumentar los ingresos propios consiste en la cláusula que obliga a adquirir los productos tintóreas y mordientes precisos en la tienda de Pedro Olzina, el cual se compromete a aplicarles los precios de coste, salvo en la cendra, que se fija a 10 s. el quintal.

Por su parte, los dos trabajadores se obligan a poner «nuestras personas al traballo e obrage del dito officio y concretamente "siamos tenidos de obrar una tina en cada una semana de nuestras proprias manos, segunt e como farian e obrarian otros dos qualesquiere obreros $*$, sin percibir por ello ningún salario; su inversión se limita, pues, al trabajo y además por debajo de su categoría profesional, salvo en el caso de que un alto rendimiento laboral permita producir al menos tres tinas a la semana, pudiendo entonces Johan Brun pasar a considerarse maestro y enon sia tenido obrar assi como obreron, o bien cuando deba atender asuntos beneficiosos para el negocio, poniendo en su lugar un hombre que lo sustituya en el trabajo manual. Es decir, solamente cuando los ingresos superen los calculados al principio de la compañía, la parte del trabajo disfrutará de ciertas prerrogativas.

Los dos socios laborantes recibirán como única compensación por los doce meses de trabajo, 35 florines de oro para sus gastos y dispondrân de un mozo que les ayude, pagado a razón de 4 dineros diarios por la sociedad. En los gastos generales se contempla la posibilidad de contratar otro personal de diferentes categorías, como son «obreros o jornaleros o moços de soldada* cuando sea necesario para cumplir los compromisos.

Al final del año, los tres asociados fijan el reparto de beneficios obtenidos tras la deducción de los gastos comunes satisfechos; estos gastos se cifran en: el alquiler del tinte; el pago de posibles salarios a los obreros, jornaleros o mozos, incluidos los 35 florines fijados a Johan Brun y Pedro de Moya y los $4 \mathrm{~d}$. diarios al mocet servidor; las expensas necesarias para la adquisición de materias primas y para desarrollar el oficio y los pagos extraordinarios mantenidos para cobrar a morosos y deudores, «Todo el residuo [...] sia en tres partes yguales partido e dividido», una para cada socio. Este reparto equitativo de los beneficios pone una nota tradicional a unos rasgos plenamente precapitalistas.

En la carta de constitución no se hace ninguna referencia al sistema de trabajo ni al tipo de producción, que queda en manos de la parte artesanal, de los clientes y, sobre todo, sujeta a las normas establecidas por el gremio y los estatutos de la ciudad. De la mención de los mordientes y tintes 
necesarios para la manufactura se deduce que la producción se basaría en tejidos de calidad media y corriente, pues el empleo de cendra en altas cantidades y gala como fijadores del color así lo dan a entender, aunque esta última sustancia fuera utilizada en la preparación de paños finos florentinos. La coloración de los tejidos abarcaría un amplio abanico, pues los tintes mencionados sirven de base a prácticamente todos los colores; así, la roja proporcionaba el colorado, asociada a la gala daba un negro muy intenso y persistente y con pastel se obtenían los apreciados tonos violeta y púrpura; la base de partida de cualquier tintura en paños de una cierta calidad era el pastel, con el que se producía el azul en todas las gamas, pero que combinado con ganda (gualda), que aislado tiñe de amarillo, se consiguen los verdes.

El final del documento notarial constituye una clara manifestación de la supremacía del capital sobre el trabajo. Apoyado en fórmulas tradicionales y en las disposiciones legales de aplicación general, Johan Brun y Pedro de Moya se ven impelidos a jurar fidelidad no sólo a la compañía, sino «al dito Pedro Olzina e a su faziendas, para preservarle de todo "danyo, perdua e menoscabo", comprometiéndose en concreto a trabajar lealmente y a declarar todos los ingresos que reciban en nombre de la sociedad, lo que corroboran mediante doble juramento ante la cruz y evangelios, acción que no realiza Pedro Olzina, que únicamente, junto a los otros dos, se obliga bajo promesa a observar y respetar los capítulos del contrato y las sanciones a aplicar a los socios que no los cumplan y ocasionen perjuicio a los demás.

En esta misma línea, aunque con posibles variantes que no podemos precisar, hay que considerar las relaciones existentes entre los ciudadanos de Zaragoza, Johan del Pin, tintorero, y Andrea Ferrer, mercader, que en febrero de 1426 mantienen una deuda de $160 \mathrm{lb} .10 \mathrm{~s}$. jaqueses con el mercader Miquel Johan, de Tortosa ${ }^{27}$. La sociedad formada por el tintorero y el mercader aragoneses presenta una ramificación hacia el exterior del reino en la persona de otro comerciante, que les aporta una cantidad importante de dinero, quizá como pago por adelantado de un encargo de trabajo, como es el caso del contrato firmado ante notario por Johan de la Raz, tintorero vecino de Zaragoza, y Nicholau Carreras, mayor de días, mercader ciudadano de Barcelona, por el cual el artesano reconoce tener en depósito del hombre de negocios catalán la cifra de $2.216 \mathrm{~s}$., que devolverá en dos plazos iguales a tres y seis meses de la fecha del documento (12 de agosto de 1427), mientras que Carreras se compromete a tomar - wha de prender»-con el primer plazo 9 «draps» obra de Zaragoza, abonando un florín por paño; y en la segunda tanda, 8 piezas, entregando, igualmente, un florín por cada una ${ }^{28}$.

27 Este Johan del Pin podría ser el hijo del citado en nota 25. AHPZ, Salvador de la Foz. 1426, f. $126-128 \mathrm{v}^{\circ}$.

${ }^{28}$ AHPZ. Salvador de la Foz, 1427, f. 294 y s. 
En conjunto, pues, en el primer cuarto del siglo XV se aprecia una íntima conexión entre el capital mercantil, natural del reino o procedente del exterior, y el trabajo, que apoyándose en el incremento de la demanda y en la existencia de una elemental estructura artesanal, impulsa la producción textil de Aragón y la canaliza hacia los mercados extranjeros. En las relaciones establecidas, el predominio de la aportación económica - no muy relevante por la simplicidad de la infraestructura necesaria- será manifiesta y aparecerán rasgos de tipo precapitalista anunciadores de las transformaciones que cuajarán en siglos posteriores. 


\section{APÉNDICE}

1401, mayo, 24. Zaragoza

Sepan todos como nos Pedro Olzina, Johan Brun e Pedro de Moya, tintureros, vezinos de la ciudat de Caragoca, todos ensenbles, conselladament e acordada, de nuestras ciertas sciencias e agradables voluntades, certificados cada uno de nos plenerament de nuestro drey, firmamos conpanya entre nos a la art e oficio de la tintureria justa e segunt la forma e manera de los capitoles por razon de la dita conpanya entre nos fazederos, feytos, concordados e por nos todos tres concordablement ordenados, el tenor de los quales yes a tal:

11/ In nomine Dei et eius infinite gratie, amen. La conpanya a la art e officio de la tintureria entre nos Pedro Olzina e Johan Brun e Pedro de Moya, en el tin o casa que nos ditos Johan Brun e Pedro de Moya e en otro lugar tenemos logado de Pero de Sant Vicient, el qual tin fue de Johan del Pin e yes agora de sus fillos, segunt la forma infrascripta.

12/ Item, yes condicion entre nos que yo dito Pedro Olzina meta e pose mil sueldos jaccenses en la dita conpanya pora sustentación e mantenimiento de la dita conpanya e de las cosas que necessarias son a la art e officio de tintureria, yes a saber en pastel, cendra, roja, ganda, galas e en todas las otras averias que son e seran necessarias a la art e officio de tintureria en quantidat de los ditos mil sueldos.

13/ Item, yes condicion que nos ditos Pedro de Moya e Johan Brun, amos ensenble e cada uno de nos por si e por el todo, reconoscamos tener en comanda de vos dito Pedro Olzina los ditos mil sueldos que vos dito Pedro Olzina posas en la dita conpanya. Enpero, que la carta de la dita obligacion finque en poder del notario entro a la fin del anyo que la dita conpanya sera finada, e cada e quando vos dito Pedro Olzina seras contento de los ditos mil sueldos, a saber yes de dineros o de ditas en buenos lugares, de manera que vos ende sias bien seguro la ora vos ditos Pedro Olzina sias tenido de cancellar la dita carta de obligacion sines todo contrastas $\mathrm{t}$.

/4/ Item, yes condicion que nos ditos Johan Brun e Pedro de Moya siamos tenidos en cada un dia sabado durant la dita conpanya, scribir de nuestra mano o del uno de nos en una cedula, todas las averias, robas que teniremos o tenyido havremos en toda la semana, la qual cedula finque e romanga en poder de vos dito Pedro Olzina a fin que vos puedas continuar vuestro conto e senblantment veas lo que si faze en cada una semana en la dita razon o conpanya.

15/ Item, yes condicion que nos ditos Johan Brun e Pedro de Moya ayamos a conprar e conpremos de vos dito Pedro Olzina todas aquellas averias que seran necessarias al dito tin, las quales vos dito Pedro Olzina sias tenido razonar ad aquel mismo precio que vos las conpraras, excepto la cendra, la qual vos sias tenido dar a diez sueldos el quintal.

16/ Item, yes condicion que nos ditos Johan Brun e Pedro de Moya o qualquier de nos, toda vegada que recibremos de vos dito Pedro Olzina aquellas averias que seran necessarias pora el dito tin, yo Pedro de Moya de mi mano propria sia tenido scrivirlas en el livro de vos dito Pedro Olzina a fer ende a vos deudo, assi como si nos las prendiessemos o conprasemos de una otra tienda o botiga. 
17/ Item, mes yes condicion que nos ditos Johan Brun e Pedro de Moya siamos tenidos dar conto a vos dito Pedro Olzina de tres en tres meses por veyer e reconexer los aferes e negocios de la dita conpanya que se trobaran, Enpero, que de la dita conpanya non puedan seyer levadas quantias algunas entro a la fin de la participacion del dito anyo, por tal que millor parezca e trobe aquello que Dios nuestro senyor hi dara.

/8/ Item, encara yes condicíon que nos ditos Johan Brun e Pedro de Moya, pora nuestra provission podamos prender e levar de la dita conpanya trenta e cinquo florines de oro pora nuestra provision e espensa, e mas quatro dineros por cada un dia pora un mocet que nos servexca. Et si de alli adelant ende havremos mas menester pora la dita nuestra provision, que nos en este caso siamos tenido de espender de nuestra propria bolsa e no de res que toque a la dita conpanya.

19/ Item, mes yes condicion que nos ditos Johan Brun e Pedro de Moya dispongamos e metamos nuestras personas al treballo e obrage del dito officio e regestamos el dito tin, hoc encara siamos tenidos de obrar una tina en cada una semana de nuestras proprias manos, segunt e como farian e obrarian otros dos qualesquiera obreros, et aquesto nos ayamos a fer e fagamos sines solucion de paga alguna que la dita conpanya aviesse ni aya a fazer ni a pagar a nos. Enpero, si en alguna semana o semanas se sdevendra que se faran tres tinas en el dito tin, que en este caso yo, dito Johan Brun, finque e romanga maestre e regidor de aquellas e yo non sia tenido obrar assi como obrero, o si algunas otras faziendas se esdevendran que fuessen e sian proveytosas a proveyto de la dita conpanya, que senblantment yo no sia tenido obrar segunt que otro obrero, mas que en lugar mia yo pueda logar un honbre pora un dia o dos o mas si mas necessario hi seran.

$/ 10 /$ Item, yes condicion que todos qualesquiere dineros que se prendran o recibran en l'obrador e tin, levantada la espenssa, contando enpero aquella en los ditos trenta e cinquo florines e mas quatro dineros por dia pora un mocet, que todo el residuo nos ditos Pedro de Moya e Johan Brun siamos tenidos dar e livrar en fin de cada una semana a vos dito Pedro Olzina. Et que vos dito Pedro Olzina sias tenido meter aquellos en recepta de aquello que a vos dito Pedro Olzina se devra por razon de las averias que de vos havremos conpradas o recebidas pora el dito tin, et ditas algunas si vos seran feytas que senblantment las recibades en conto e en paga de las ditas averias.

111/ Iten, encara mas yes condicion que cada e quando los ditos mil sueldos seran enprados e espendidos en los aferes e negocios de la dita conpanya, que en este caso vos dito Pedro Olzina sias tenido de meter hi otros mil solidos o todos aquellos dineros que y seran necessarios, en aquellas averias que y seran menester al dito tin, segunt que dito yes. Enpero, que nos ditos Johan Brun e Pedro de Moya siamos tenidos de contentar e contentemos a vos dito Pedro Olzina de los primeros mil sueldos en dineros o en ditas en buenos lugares e seguros. Enpero, si contece, lo que Dios no mande, que si apres que seran a vos feytas las ditas contecia que alguna o algunas de aquellas non sen podrian cobrar de los deudores e aquesto por razon que alguno o algunos dellos sen hiva o yran de la dita ciudat, se muria o murran o por qualque otro excesso, caso, manera o razon, que en este caso vos dito Pedro Olzina non podades perder ni perdades alguna cosa de todo aquello, antes la dita conpanya sia e finque tenida de recebir e reciba aquellas ditas en si e contente a vos dito Pedro Olzina de todo aquello que en el dito caso deve seyer contentado. Et si por ventura por cobrar alguna o algunas tales ditas o deudos se convinian o 
convendran fer algunas espenssas e messiones, que tales como aquellas se conten al comun de la dita conpanya pues por cobrar los deudos de aquella seran feytas.

/12/ Item, mas yes condicion que del comun de la dita conpanya sia pagado e se pague el loguero del tin e qualesquiere otros obreros o jornaleros o moços de soldada necessarios al obrage del dito tin e qualesquiere otras espensas que se faran por causa e razon de provey to e utilidat de la dita conpanya, todo aquello se pague del comun de la dita conpanya segunt dito yes.

113/ Item, encara yes condicion que levantados e pagados los ditos trenta e cinquo florines de la espensa de nos ditos Johan Brun e Pedro de Moya, e los quatro dineros por dia del mocet servidor si allo finquara, e todas e qualesquiere otras espenssas que justament e licita seran feytas e espendidas por proveyto e utilidat de la dita conpanya, todo el residuo que nuestro senyor Dios hi dara en la dita razon e conpanya, sia en tres partes yguales partido e dividido, de las quales tres partes yguales yo dito Pedro Olzina prenga la una e vos ditos Johan Brun e Pedro de Moya las ditas partes, segunt que dito yes.

/14/ Item, yes encara condicion que por mayor firmeza e seguridat de la cosa et por mellor seyer de la conpanya, nos ditos Johan Brun e Pedro de Moya juremos sobre la cruz e los santos quatro evangelios de nuestro senyor Jhesu Christo que nos tendremos e conpliremos e observaremos todas e cada unas cosas en los presentes e infrascriptos capitoles contenidas c guardaremos e redraremos al dito Pedro Olzina e a su fazienda de todo danyo, perdua e menoscabo por todo nuestro poder e saber que a nuestra noticia pervendra, et que nos hayamos e havremos bien e lealment en la dita conpanya e adozir bien e lealment a buena, verdadera e leal particion todo aquello que nuestro senyor Dios por merced suya bi querra dar e ministrar durant tiempo del dito anyo e conpanya, segunt que entre buenos e leales e verdaderos conpanyeros se deve e yes costunbrado fazer.

La qual conpanya e razon nos ditos Pedro Olzina, Johan Brun e Pedro de Moya prometemos e nos obligamos fer e tener, conplir e observar, bien, entregament e conplida como e segunt en los preinsertos capitoles por todos nos concordablement feytos e ordenados y es mas largament contenido, especificado e declarado. Et si por ventura alguno o algunos de nos no tendremos, conpliremos e observaremos todas e cada unas cosas sobreditas e en el present contracto e capitoles contenidas et por aquella razon a los otros ho alguno de los otros convendra fer messiones, danyos o menoscabos algunos sostener en qualquiere manera, todos aquellos $\mathrm{e}$ aquellas prometemos e nos obligamos bien e conplidament pagar, emendar e satisfer, de los quales danyos, messiones e menoscabos e de todo lo sobredito queremos que qualquiere de nos sia en el caso sobredito creydo por su sinple palabra sines jura e toda otra manera de promesion requerida. Et por tener, conplir e observar todo lo sobredito obligamos los unos a los otros todos nuestros bienes e de cada uno de nos, mobles e sedientes, havidos e por haver en todo lugar. Encara prometemos, cometemos e nos obligamos haver, dar e asignar bienes nuestros e de cada uno de nos proprios, mobles, quitos e desenbargados dentro de nuestras casas e de quien que havremos a conplimiento de todas e cada unas cosas sobreditas, los quales queremos que ende puedan seyer feytos sacar e vender luego a uso e costunbre de cort e de alfarda segunt que uso e costunbre yes en Caragoca de vender, penyorar de alfarda, feytas con solament aquellas tres almonedas por tres dias e renunciamos dia de acuerdo e diez dias pora cartas demandar. Et non resmenos nos ditos Johan Brun e Pedro de Moya por mayor firmeza e seguridat de 
todas e cada unas cosas sobreditas e por mayor corroboracion del present contracto e cosas en aquel contenidas, juramos sobre la cruz e los sanctos quatro evangelios de nuestro senyor Jhesu Christo ante nos e cada uno de nos puestos e por cada uno de nos manualment e corporal tocados que nos e cada uno de nos tendremos, conpliremos e observaremos todas e cada unas cosas en el present contracto e capitoles contenidas por todo nuestro poder, saber e entender e no cuentravenir ni fer venir por nos ni por otrí o otros por nos, ocultament ni manifiesta en alguna manera, assi nuestro senyor Dios e aquestos santos quatro evangelios de nuestro senyor Jhesu Christo nos ayuden, amen.

Fey to fue esto en la ciudat de Caragoca a vint e quatro dias del mes de mayo, anyo a nativitate domini millesimo quadringentesimo primo.

Presentes testimonios son de aquesto Guillen de Burguesa notario, e Gutierrez d'Almaçan, vezinos de la dita ciudat.

(AHPZ, Juan Blasco de Azuara 1401, registro, s.d., s.f. Protocolo, f. 302-305 vo.) 